PAPER

\title{
Detection of focal cerebral hemisphere lesions using the neurological examination
}

\author{
N E Anderson, D F Mason, J N Fink, P S Bergin, A J Charleston, G D Gamble
}

J Neurol Neurosurg Psychiatry 2005;76:545-549. doi: 10.1136/jnnp.2004.043679

See end of article for authors' affiliations .....................

Correspondence to: Dr Neil Anderson, Department of Neurology, Auckland Hospital, Private Bag 92024, Auckland, New Zealand; neila@ adhb.govt.nz

Received 18 April 2004 In revised form 16 July 2004

Accepted 4 August 2004
Objective: To determine the sensitivity and specificity of clinical tests for detecting focal lesions in a prospective blinded study.

Methods: 46 patients with a focal cerebral hemisphere lesion without obvious focal signs and 19 controls with normal imaging were examined using a battery of clinical tests. Examiners were blinded to the diagnosis. The sensitivity, specificity, and positive and negative predictive values of each test were measured.

Results: The upper limb tests with the greatest sensitivities for detecting a focal lesion were finger rolling (sensitivity 0.33 (95\% confidence interval, 0.21 to 0.47$)$ ), assessment of power $(0.30(0.19$ to 0.45$)$ ), rapid alternating movements $(0.30(0.19$ to 0.45$))$, forearm rolling $(0.24(0.14$ to 0.38$))$, and pronator drift $(0.22(0.12$ to 0.36$))$. All these tests had a specificity of $1.00(0.83$ to 1.00$)$. This combination of tests detected an abnormality in $50 \%$ of the patients with a focal lesion. In the lower limbs, assessment of power was the most sensitive test (sensitivity $0.20(0.11$ to 0.33$)$ ). Visual field defects were detected in 10 patients with a focal lesion (sensitivity $0.22(0.12$ to 0.36$)$ ) and facial weakness in eight (sensitivity 0.17 (0.09 to 0.31 )). Overall, the examination detected signs of focal brain disease in $61 \%$ of the patients with a focal cerebral lesion.

Conclusions: The neurological examination has a low sensitivity for detecting early cerebral hemisphere lesions in patients without obvious focal signs. The finger and forearm rolling tests, rapid alternating movements of the hands, and pronator drift are simple tests that increase the detection of a focal lesion without greatly increasing the length of the examination.
$\mathrm{T}$ he neurological examination is often used to decide whether a patient presenting with non-focal neurological symptoms, such as headache, should be investigated with brain imaging. Only a few studies have measured the sensitivity and specificity of individual components of the neurological examination, ${ }^{12}$ and most of the clinical tests used to detect focal brain disease have not been investigated in this way. Our aim in this study was to determine which clinical tests are most useful in detecting a cerebral hemisphere lesion. The tests were evaluated in patients resembling those who present in general practice or the outpatient clinic with early neurological disease. Patients with an obvious neurological deficit were excluded. A control group of patients without focal brain disease was included and examiners were blinded to the diagnosis. The study was approved by the Auckland ethics committee.

\section{METHODS \\ Patients}

Focal lesion group

Forty six patients ( 28 men and 18 women) aged 21 to 83 years (mean 51) had a single cerebral hemisphere lesion identified on computed tomography (CT) (23 patients), or on both CT and magnetic resonance imaging (MRI) (22 patients). One patient had MRI only. Their clinical and radiological features are presented in table 1. Seventeen patients had presented with focal neurological symptoms: partial epilepsy (9), hemiparesis (4), transient ischaemic attacks (2), hemisensory symptoms (1), and homonymous hemianopia (1). Twenty eight patients had non-focal symptoms: headache (13), epilepsy without focal features (9), change in cognitive function (3), light headedness (1), blurred vision (1), and lethargy (1). One patient did not have neurological symptoms. Focal signs had been detected before recruitment in 16 patients $(35 \%)$ : subtle upper motor neurone signs (9), homonymous hemianopia (5), hemisensory signs (1), and apraxia (1).

Patients were excluded if they had an obvious hemiparesis, aphasia, or gait disorder, or if drowsiness or cognitive impairment affected their cooperation with the neurological examination. Patients with brain stem or cerebellar lesions, movement disorders, non-neurological disorders that hindered neurological assessment, or a marked midline shift associated with a focal brain lesion, were also excluded.

\section{Control group}

Nineteen patients who had been referred for investigation of headaches (13) or transient neurological events (epilepsy, transient ischaemic attack, syncope, psychogenic pseudoseizures, labyrinthitis, and an unspecified transient neurological event in one patient each) but had normal imaging formed the control group. One control patient had MRI only; the others were investigated with CT, with or without MRI. Only the patient presenting with a transient ischaemic attack had focal neurological symptoms. None had focal signs before recruitment in the study.

\section{Sample size}

The sample size was determined by simulating the width of the 95\% confidence intervals (CI) around a theoretical sensitivity, specificity, positive predictive value, and negative predictive value of $50 \%$. A sample size of 100 was conservatively estimated to provide precision of the 95\% CI to within $15 \%$. It was recognised that fewer cases would be required if the discriminability of a test was either very good or very poor, so provision was made for an interim examination to determine the final sample size. At least 60 cases were required to determine the precision of the sensitivity and specificity of the various tests to within 15\%. 
Table 1 Clinical and radiological features in 46 patients with a single focal brain lesion

\begin{tabular}{llr}
\hline Variable & & $\mathbf{n}(\%)$ \\
\hline Affected hemisphere & Right & $22(48)$ \\
& Left & $24(52)$ \\
& Intra-axial & $39(85)$ \\
Location & Extra-axial & $7(15)$ \\
& Frontal & $20(43)$ \\
Affected lobe* & Temporal & $13(28)$ \\
& Parietal & $16(35)$ \\
& Occipital & $8(17)$ \\
& Tumour & $36(78)$ \\
Diagnosis & Infarct & $5(11)$ \\
& Cavernous angioma & $3(7)$ \\
& Intracerebral haematoma & $2(4)$ \\
Handedness & Right & $35(76)$ \\
& Left & $7(15)$ \\
& Ambidextrous & $1(2)$ \\
& Not recorded & $3(7)$ \\
\hline \multirow{2}{*}{ *Lesion involved more than one lobe in 11 patients $(24 \%)}$.
\end{tabular}

\section{Neurological examination}

Each patient was examined by one of us. The examiner was informed of the patient's age and handedness. Other clinical data and the results of imaging were not provided. The examiner did not obtain a history from the patients or their relatives. For each clinical test, the findings were graded as normal or abnormal. Equivocal abnormalities were classified as normal. Unilateral abnormalities were analysed together, regardless of whether the abnormal sign was ipsilateral or contralateral to the lesion. Although signs ipsilateral to the lesion were falsely localising, in practice they would have stimulated investigation for a focal lesion. When a sign was abnormal bilaterally, it was classified as normal, because it would be unhelpful in identifying focal brain disease.

\section{Motor examination}

The motor examination of the limbs included standard tests of tone, power, tendon reflexes, plantar responses, and coordination. ${ }^{3}$ Asterixis, Hoffmann's sign, Wartenberg's sign, grasp reflex, and palmomental reflex were assessed using standard techniques. ${ }^{34}$
Drift in the upper limbs was assessed by asking the patient to sit with eyes closed, both arms outstretched and forearms supinated for 10 seconds.

In the shoulder shrug test, the speed of the movement on the two sides was compared.

Rapid finger movements were assessed by repeatedly tapping the tip of the thumb and index finger for 10 seconds (thumb to index finger) and by tapping the thumb sequentially with each finger, starting with the index finger (thumb to all fingers).

Rapid alternating movements in the upper limbs were tested by patting the thigh alternately with the dorsum or palm for 10 seconds, and by rapidly extending and flexing the fingers of each hand for 10 seconds ("fist opening/closing").

In the forearm rolling test, each forearm was rapidly rotated around the other for five seconds in each direction. ${ }^{1}$ An abnormal response was recorded if one forearm orbited around the other. In the finger rolling test each index finger was rotated around the other for five seconds in each direction. ${ }^{5}$ An abnormal response was present if one finger orbited around the other. ${ }^{5}$

Rapid alternating movements of the feet were assessed by rapidly tapping the floor with the forefoot, while the heel was resting on the floor (foot tapping), and by shaking each foot up and down for five seconds while the patient was lying (foot shaking).

Ability to balance on each foot was assessed with the patient's eyes closed. Symmetry of arm swing was noted during walking.

\section{Sensory examination}

The sensory examination included discrimination of light touch and pin prick, position sense (thumb finding, toe finding, finger-nose and heel-knee tests, and passive joint position sensation), two point discrimination, localisation of tactile stimuli (topagnosia), sensory extinction, graphaesthesia, and stereognosis. ${ }^{3}$ Sensation was tested in the arms and legs, but not on the trunk or face.

\section{Cranial nerves and vision}

Visual fields were tested by asking the patient to detect fine finger movements and colour desaturation with a $5 \mathrm{~mm}$ diameter red object in each quadrant of the visual fields. The speed and power of facial movements were assessed in

Table 2 Sensitivity, specificity, positive predictive value, and negative predictive value for motor signs in the upper limbs

\begin{tabular}{|c|c|c|c|c|c|c|c|c|}
\hline & \multicolumn{2}{|c|}{$\begin{array}{l}\text { Focal lesion } \\
(n=46)\end{array}$} & \multicolumn{2}{|c|}{$\begin{array}{l}\text { Controls } \\
(n=19)\end{array}$} & \multirow[b]{2}{*}{ Sensitivity $(95 \% \mathrm{Cl})$} & \multirow[b]{2}{*}{ Specificity $(95 \% \mathrm{CI})$} & \multirow[b]{2}{*}{ PPV $(95 \% \mathrm{CI})$} & \multirow[b]{2}{*}{ NPV $(95 \% \mathrm{Cl})$} \\
\hline & Pos & Neg & Pos & Neg & & & & \\
\hline Finger rolling & 15 & 31 & 0 & 19 & $0.33(0.21$ to 0.47$)$ & $1.00(0.83$ to 1.00$)$ & $1.00(0.78$ to 1.00$)$ & $0.38(0.25$ to 0.51$)$ \\
\hline UMN weakness & 14 & 32 & 0 & 19 & $0.30(0.19$ to 0.45$)$ & $1.00(0.83$ to 1.00$)$ & $1.00(0.76$ to 1.00$)$ & $0.37(0.24$ to 0.51$)$ \\
\hline RAM & 14 & 32 & 0 & 19 & $0.30(0.19$ to 0.45$)$ & $1.00(0.83$ to 1.00$)$ & $1.00(0.76$ to 1.00$)$ & $0.37(0.24$ to 0.51$)$ \\
\hline Forearm rolling & 11 & 35 & 0 & 19 & $0.24(0.14$ to 0.38$)$ & $1.00(0.83$ to 1.00$)$ & $1.00(0.70$ to 1.00$)$ & 0.35 (0.22 to 0.48$)$ \\
\hline Pronator drift & 10 & 36 & 0 & 19 & $0.22(0.12$ to 0.36$)$ & $1.00(0.83$ to 1.00$)$ & $1.00(0.69$ to 1.00$)$ & $0.35(0.22$ to 0.47$)$ \\
\hline Unilateral $\downarrow$ arm swing & 10 & 36 & 2 & 17 & $0.22(0.12$ to 0.36$)$ & 0.89 (0.69 to 0.97$)$ & $0.83(0.51$ to 0.98$)$ & $0.32(0.20$ to 0.45$)$ \\
\hline Tapping thumb to fingers & 9 & 37 & 0 & 19 & $0.20(0.11$ to 0.33$)$ & $1.00(0.83$ to 1.00$)$ & $1.00(0.66$ to 1.00$)$ & $0.34(0.22$ to 0.46$)$ \\
\hline Fist opening/closing & 7 & 39 & 0 & 19 & $0.15(0.08$ to 0.28$)$ & $1.00(0.83$ to 1.00$)$ & $1.00(0.59$ to 1.00$)$ & $0.33(0.21$ to 0.45$)$ \\
\hline $\begin{array}{l}\text { Tapping thumb to index } \\
\text { finger }\end{array}$ & 7 & 39 & 0 & 19 & $0.15(0.08$ to 0.28$)$ & $1.00(0.83$ to 1.00$)$ & $1.00(0.59$ to 1.00$)$ & $0.33(0.21$ to 0.45$)$ \\
\hline Shoulder shrug & 5 & 41 & 0 & 19 & $0.11(0.05$ to 0.23$)$ & $1.00(0.83$ to 1.00$)$ & $1.00(0.47$ to 1.00$)$ & $0.32(0.20$ to 0.43$)$ \\
\hline Hyperreflexia & 5 & 41 & 1 & 18 & $0.11(0.05$ to 0.23$)$ & 0.95 (0.75 to 0.99$)$ & $0.83(0.39$ to 0.99$)$ & 0.31 (0.19 to 0.42$)$ \\
\hline Wartenberg's sign & 5 & 41 & 1 & 18 & $0.11(0.05$ to 0.23$)$ & 0.95 (0.75 to 0.99$)$ & 0.83 (0.35 to 0.99$)$ & 0.31 (0.19 to 0.42$)$ \\
\hline Palmomental reflex & 5 & 41 & 1 & 18 & 0.11 (0.05 to 0.23$)$ & 0.95 (0.75 to 0.99$)$ & $0.83(0.35$ to 0.99$)$ & 0.31 (0.19 to 0.42$)$ \\
\hline Hoffmann's sign & 2 & 44 & 0 & 19 & $0.04(0.01$ to 0.15$)$ & $1.00(0.83$ to 0.99$)$ & $1.00(0.15$ to 1.00$)$ & $0.30(0.19$ to 0.41$)$ \\
\hline Spasticity & 2 & 44 & 0 & 19 & $0.04(0.01$ to 0.15$)$ & $1.00(0.83$ to 1.00$)$ & $1.00(0.15$ to 1.00$)$ & $0.30(0.19$ to 0.41$)$ \\
\hline Unilateral asterixis & 1 & 45 & 0 & 19 & $0.02(0.00$ to 0.11$)$ & $1.00(0.83$ to 1.00$)$ & $1.00(0.20$ to 1.00$)$ & $0.30(0.18$ to 0.41$)$ \\
\hline Unilateral grasp reflex & 0 & 46 & 0 & 19 & $0.00(0.00$ to 0.08$)$ & $1.00(0.83$ to 1.00$)$ & - & $0.29(0.18$ to 0.40$)$ \\
\hline
\end{tabular}


Table 3 Sensitivity, specificity, positive predictive value, and negative predictive value for motor signs in the lower limbs

\begin{tabular}{|c|c|c|c|c|c|c|c|c|}
\hline & \multicolumn{2}{|c|}{$\begin{array}{l}\text { Focal lesion } \\
(n=46)\end{array}$} & \multicolumn{2}{|c|}{$\begin{array}{l}\text { Controls } \\
(n=19)\end{array}$} & \multirow[b]{2}{*}{ Sensitivity (95\% Cl) } & \multirow[b]{2}{*}{ Specificity $(95 \%$ Cl) } & \multirow[b]{2}{*}{ PPV (95\% Cl) } & \multirow[b]{2}{*}{ NPV $(95 \%$ Cl) } \\
\hline & Pos & $\mathrm{Neg}$ & Pos & $\mathrm{Neg}$ & & & & \\
\hline $\begin{array}{l}\text { UMN weakness } \\
\text { Impaired balance on one }\end{array}$ & 9 & 37 & 0 & 19 & 0.20 (0.11 to 0.33$)$ & $1.00(0.83$ to 1.00$)$ & $1.00(0.66$ to 1.00$)$ & $0.34(0.22$ to 0.46$)$ \\
\hline foot & 9 & 37 & 5 & 14 & $0.20(0.11$ to 0.33$)$ & $0.74(0.51$ to 0.88$)$ & $0.64(0.35$ to 0.89$)$ & $0.27(0.15$ to 0.40$)$ \\
\hline Extensor plantar & 6 & 40 & 0 & 19 & $0.13(0.06$ to 0.26$)$ & $1.00(0.83$ to 1.00$)$ & $1.00(0.54$ to 1.00$)$ & $0.32(0.20$ to 0.44$)$ \\
\hline Foot tapping & 5 & 41 & 2 & 17 & 0.11 (0.05 to 0.23$)$ & 0.89 (0.69 to 0.97$)$ & $0.71(0.29$ to 0.97$)$ & $0.29(0.18$ to 0.41$)$ \\
\hline Spasticity & 4 & 42 & 0 & 19 & $0.09(0.03$ to 0.20$)$ & $1.00(0.83$ to 1.00$)$ & $1.00(0.39$ to 1.00$)$ & 0.31 (0.20 to 0.43$)$ \\
\hline Foot shaking & 4 & 42 & 2 & 17 & $0.09(0.03$ to 0.20$)$ & 0.89 (0.69 to 0.97 ) & $0.67(0.22$ to 0.97$)$ & $0.29(0.17$ to 0.40$)$ \\
\hline
\end{tabular}

response to command and during emotional responses. Optokinetic nystagmus was tested in the horizontal plane. ${ }^{67}$

\section{Language and cognitive skills}

The assessment of language included tests of naming, and repetition of phrases and sentences. To test auditory comprehension, the patient was asked to follow verbal commands. Writing was assessed by asking the patient to write their name, address, and a sentence. The patient was asked to read aloud and perform a written command. Mental arithmetic was tested by asking the patient to add or subtract one and two digit numbers. Left-right discrimination was tested by asking the patient to identify digits in each hand. Constructional skills were assessed by copying a figure depicting intersecting pentagons and drawing a clock face.

\section{Analyses}

At the conclusion of the examination, the examiner was asked to answer the following questions: Is a focal cerebral hemisphere lesion present? If present, which side of the brain is affected by the lesion?

The sensitivity, specificity, and positive and negative predictive values were calculated for each test. Confidence intervals were calculated using the Wilson score method without continuity correction. ${ }^{8}$

\section{RESULTS}

\section{Upper limb motor tests}

The results of these tests are shown in table 2 . The most sensitive tests for detecting a focal lesion were abnormal finger rolling, upper motor neurone weakness, impaired rapid alternating movements, abnormal forearm rolling, and pronator drift. An abnormal finger rolling test was found in
15 patients $(33 \%)$, five of whom had normal power. An abnormal finger or forearm rolling test was present in 16 patients (35\%) with a focal lesion. Fourteen patients $(30 \%)$ had impaired rapid alternating movements, including four patients with normal power. Three of these patients also had normal forearm and finger rolling tests. Pronator drift was present in 10 patients (22\%) with a focal lesion; four of these patients had normal upper limb power. The combination of testing power and rapid alternating movements in the arms, forearm and finger rolling and pronator drift detected one or more abnormalities in $50 \%$ of the patients with a focal lesion.

Tests of rapid finger movements were less sensitive. Finger tapping tests were judged to be abnormal in the nondominant hand ipsilateral to the lesion in four patients with a focal lesion, but these tests were normal in the control patients. Ten patients $(22 \%)$ with a focal lesion had a unilateral reduction in arm swing while walking, but in four of these patients the affected arm was ipsilateral to the lesion. Two control patients had unilateral loss of arm swing. Bilateral palmomental reflexes were present in $15 \%$ of the patients with a focal lesion and 5\% of the control group. Wartenberg's sign was present bilaterally in $17 \%$ of the focal lesion group and $11 \%$ of the controls. The other signs were abnormal in only a few patients with a focal lesion.

\section{Lower limb motor tests}

Unilateral upper motor neurone weakness and impaired ability to stand on one foot with eyes closed were the most frequent motor signs in the legs in the focal lesion group (table 3). Five control patients $(26 \%)$ had difficulty in balancing on one foot. Five of the six patients with an extensor plantar response had other signs in the same leg.

Table 4 Sensitivity, specificity, positive predictive value, and negative predictive value for sensory signs

\begin{tabular}{|c|c|c|c|c|c|c|c|c|}
\hline & \multicolumn{2}{|c|}{$\begin{array}{l}\text { Focal lesion } \\
(n=46)\end{array}$} & \multicolumn{2}{|c|}{$\begin{array}{l}\text { Controls } \\
(n=19)\end{array}$} & \multirow[b]{2}{*}{ Sensitivity $(95 \% \mathrm{Cl})$} & \multirow[b]{2}{*}{ Specificity $(95 \% \mathrm{Cl})$} & \multirow[b]{2}{*}{ PPV $(95 \% \mathrm{Cl})$} & \multirow[b]{2}{*}{ NPV $(95 \% \mathrm{CI})$} \\
\hline & Pos & Neg & Pos & Neg & & & & \\
\hline $\begin{array}{l}\text { Two point } \\
\text { discrimination }\end{array}$ & 9 & 37 & 1 & 18 & $0.20(0.11$ to 0.33$)$ & $0.95(0.75$ to 0.99$)$ & $0.90(0.55$ to 0.99$)$ & $0.33(0.20$ to 0.45$)$ \\
\hline Graphaesthesia & 6 & 40 & 0 & 19 & $0.13(0.06$ to 0.26$)$ & $1.00(0.83$ to 1.00$)$ & $1.00(0.54$ to 1.00$)$ & $0.32(0.20$ to 0.44$)$ \\
\hline Thumb finding & 5 & 41 & 0 & 19 & $0.11(0.05$ to 0.23$)$ & $1.00(0.83$ to 1.00$)$ & $1.00(0.47$ to 1.00$)$ & $0.32(0.20$ to 0.43$)$ \\
\hline Sensory extinction & 5 & 41 & 0 & 19 & $0.11(0.05$ to 0.23$)$ & $1.00(0.83$ to 1.00$)$ & $1.00(0.47$ to 1.00$)$ & $0.32(0.20$ to 0.43$)$ \\
\hline Stereognosis & 5 & 41 & 1 & 18 & $0.11(0.05$ to 0.23$)$ & 0.95 (0.75 to 0.99$)$ & $0.83(0.35$ to 0.99$)$ & 0.31 (0.19 to 0.42$)$ \\
\hline Finger-nose & 4 & 42 & 1 & 18 & $0.09(0.03$ to 0.20$)$ & 0.95 (0.75 to 0.99$)$ & $0.80(0.28$ to 0.99$)$ & $0.30(0.18$ to 0.42$)$ \\
\hline Pinprick & 2 & 44 & 0 & 19 & $0.04(0.01$ to 0.15$)$ & $1.00(0.83$ to 1.00$)$ & $1.00(0.15$ to 1.00$)$ & $0.30(0.19$ to 0.41$)$ \\
\hline Passive joint position & 2 & 44 & 0 & 19 & $0.04(0.01$ to 0.15$)$ & $1.00(0.83$ to 1.00$)$ & $1.00(0.15$ to 1.00$)$ & $0.30(0.19$ to 0.41$)$ \\
\hline Toe finding & 2 & 44 & 1 & 18 & $0.04(0.01$ to 0.15$)$ & $0.95(0.75$ to 0.99$)$ & $0.67(0.09$ to 0.99$)$ & $0.29(0.18$ to 0.40$)$ \\
\hline Light touch & 1 & 45 & 0 & 19 & $0.02(0.00$ to 0.11$)$ & $1.00(0.83$ to 1.00$)$ & $1.00(0.02$ to 1.00$)$ & $0.30(0.18$ to 0.41$)$ \\
\hline Topagnosia & 1 & 45 & 0 & 19 & $0.02(0.00$ to 0.11$)$ & $1.00(0.83$ to 1.00$)$ & $1.00(0.02$ to 1.00$)$ & $0.30(0.18$ to 0.41$)$ \\
\hline Heel-knee & 0 & 46 & 0 & 19 & $0.00(0.00$ to 0.08$)$ & $1.00(0.83$ to 1.00$)$ & - & $0.29(0.18$ to 0.40$)$ \\
\hline
\end{tabular}


Table 5 Sensitivity, specificity, positive predictive value and negative predictive value of cranial nerve signs

\begin{tabular}{|c|c|c|c|c|c|c|c|c|}
\hline & \multicolumn{2}{|c|}{$\begin{array}{l}\text { Focal lesion } \\
(n=46)\end{array}$} & \multicolumn{2}{|c|}{$\begin{array}{l}\text { Controls } \\
(n=19)\end{array}$} & \multirow[b]{2}{*}{ Sensitivity $(95 \% \mathrm{Cl})$} & \multirow[b]{2}{*}{ Specificity $(95 \% \mathrm{CI})$} & \multirow[b]{2}{*}{$\operatorname{PPV}(95 \% \mathrm{Cl})$} & \multirow[b]{2}{*}{ NPV $(95 \% \mathrm{Cl})$} \\
\hline & Pos & Neg & Pos & $\mathrm{Neg}$ & & & & \\
\hline Visual field defect & 10 & 36 & 1 & 18 & $0.22(0.12$ to 0.36$)$ & 0.95 (0.75 to 0.99$)$ & $0.91(0.58$ to 0.99$)$ & $0.33(0.21$ to 0.46$)$ \\
\hline Facial weakness & 8 & 38 & 1 & 18 & $0.17(0.09$ to 0.31$)$ & 0.95 (0.75 to 0.99$)$ & $0.89(0.51$ to 0.99$)$ & $0.32(0.20$ to 0.44$)$ \\
\hline Optokinetic nystagmus & 6 & 40 & 0 & 19 & $0.13(0.06$ to 0.26$)$ & 1.00 (0.83 to 1.00$)$ & $1.00(0.54$ to 1.00$)$ & $0.32(0.20$ to 0.44$)$ \\
\hline
\end{tabular}

\section{Sensation}

The results of sensation testing are shown in table 4. Two point discrimination was abnormal in nine patients $(20 \%)$. The abnormality was contralateral to the lesion in seven patients and ipsilateral in two. One patient with a focal lesion had unilateral astereognosis and graphaesthesia without other focal signs. The remaining patients with abnormal sensory signs had other abnormalities on the neurological examination.

\section{Cranial nerve examination}

The results of cranial nerve examination are shown in table 5. A homonymous hemianopia or quadrantanopia was found in 10 patients $(22 \%)$. Nine of these patients had at least one other abnormal clinical test. Upper motor neurone facial weakness was present in eight patients $(17 \%)$ with a focal lesion, but all had other focal abnormalities.

\section{Tests of cognitive function}

The results of tests of cognitive function are shown in table 6. The sensitivities of impaired naming and impaired constructional ability for detecting a focal brain lesion were 0.20 or more, but neither test reliably lateralised the lesion. The lesion was in the non-dominant hemisphere in four of the nine patients with impaired naming. Of the 14 patients with impaired constructional ability, the lesion was in the dominant hemisphere in seven and in the non-dominant hemisphere in seven.

\section{Overall impression}

The examiner identified the presence and side of the lesion in $27(59 \%)$ of the patients with a focal lesion. In one patient the examiner thought there was a focal lesion but incorrectly identified the affected side. In 18 patients (39\%) the examiner found no evidence of a focal lesion. Three patients $(16 \%)$ in the control group were incorrectly thought to have a focal lesion.

\section{DISCUSSION}

Overall, the neurological examination had a low sensitivity for the detection of a focal cerebral hemisphere lesion in these selected patients. In the upper limb examination, the signs with the greatest sensitivity and specificity for detecting a focal cerebral lesion were an upper motor neurone pattern of weakness, abnormal forearm or finger rolling test, pronator drift, and impaired rapid alternating movements. This combination of tests detected an abnormality in 50\% of the patients with a focal lesion, representing a sensitivity that was not much less than the sensitivity for the whole battery of neurological tests.

The finger rolling test was abnormal in one third of the patients with a focal lesion, a lower sensitivity than reported previously for the forearm and finger rolling tests. ${ }^{15}$ This difference between studies is probably explained by differences in the patient populations.

A positive pronator drift test was present in $22 \%$ of patients in the focal lesion group. In other studies a higher proportion of patients with a focal lesion showed pronator drift. ${ }^{12}$ Again, the difference between the studies may be explained by patient selection, but variation in technique is another possible explanation. We asked our patients to hold their arms supine for 10 seconds, ${ }^{9}$ but pronator drift may be more apparent if the arms are held in this position for longer and if finger spreading is checked. ${ }^{2}$

Finger tapping tests were abnormal in less than 20\% of the patients with a focal lesion. Interpretation of finger tapping can be difficult, because performance may be slower in the non-dominant hand in normal people. ${ }^{10}$ Hoffmann's sign, Wartenberg's sign, and unilateral asterixis may be early indicators of a unilateral cerebral hemisphere lesion, ${ }^{41}$ but in our study these tests were seldom abnormal in patients with a focal lesion. A grasp reflex was not found in any of our patients. Grasping is observed in patients with frontal lobe lesions, but even when the lesion is unilateral, grasping usually affects both hands. ${ }^{12}$

Table 6 Sensitivity, specificity, positive predictive value, and negative predictive value of cognitive tests*

\begin{tabular}{|c|c|c|c|c|c|c|c|c|}
\hline & \multicolumn{2}{|c|}{$\begin{array}{l}\text { Focal lesion } \\
(n=46)\end{array}$} & \multicolumn{2}{|c|}{$\begin{array}{l}\text { Controls } \\
(n=19)\end{array}$} & \multirow[b]{2}{*}{ Sensitivity $(95 \% \mathrm{Cl})$} & \multirow[b]{2}{*}{ Specificity $(95 \% \mathrm{Cl})$} & \multirow[b]{2}{*}{ PPV $(95 \% \mathrm{Cl})$} & \multirow[b]{2}{*}{ NPV $(95 \%$ Cl) } \\
\hline & Pos & Neg & Pos & Neg & & & & \\
\hline Construction & 14 & 32 & 2 & 17 & $0.30(0.19$ to 0.45$)$ & $0.89(0.69$ to 0.97$)$ & $0.88(0.64$ to 0.97$)$ & $0.35(0.23$ to 0.49$)$ \\
\hline Naming & 9 & 35 & 0 & 17 & $0.20(0.11$ to 0.35$)$ & $1.00(0.82$ to 1.00$)$ & $1.00(0.70$ to 1.00$)$ & $0.33(0.22$ to 0.46$)$ \\
\hline Calculation & 8 & 38 & 1 & 18 & $0.17(0.09$ to 0.31$)$ & $0.95(0.75$ to 0.99$)$ & 0.89 (0.57 to 0.98$)$ & $0.32(0.21$ to 0.45$)$ \\
\hline Repetition & 7 & 37 & 2 & 15 & $0.16(0.08$ to 0.29$)$ & $0.88(0.66$ to 0.97$)$ & $0.78(0.45$ to 0.94$)$ & $0.29(0.18$ to 0.42$)$ \\
\hline Finger naming & 7 & 39 & 1 & 18 & 0.15 (0.08 to 0.28$)$ & 0.95 (0.75 to 0.99$)$ & 0.88 (0.53 to 0.98$)$ & $0.32(0.21$ to 0.44$)$ \\
\hline $\begin{array}{l}\text { Auditory } \\
\text { comprehension }\end{array}$ & 4 & 41 & 0 & 18 & $0.09(0.04$ to 0.21$)$ & $1.00(0.82$ to 1.00$)$ & $1.00(0.51$ to 1.00$)$ & $0.31(0.20$ to 0.43$)$ \\
\hline Reading & 4 & 41 & 0 & 18 & $0.09(0.04$ to 0.21$)$ & $1.00(0.82$ to 1.00$)$ & $1.00(0.51$ to 1.00$)$ & $0.31(0.20$ to 0.43$)$ \\
\hline Writing & 4 & 41 & 0 & 18 & 0.09 (0.04 to 0.21$)$ & $1.00(0.82$ to 1.00$)$ & $1.00(0.51$ to 1.00$)$ & $0.31(0.20$ to 0.43$)$ \\
\hline Right-left & & & & & & & & \\
\hline discrimination & 2 & 44 & 0 & 19 & $0.04(0.01$ to 0.15$)$ & $1.00(0.83$ to 1.00$)$ & $1.00(0.34$ to 1.00$)$ & $0.30(0.20$ to 0.42$)$ \\
\hline
\end{tabular}


Assessment of the visual fields may be helpful in identifying focal brain disease, because patients may not be aware of a visual field defect. If the lesion is in the occipital lobe, the remainder of the examination may be normal. In this study, however, all but one of the patients with a visual field abnormality had other abnormal signs. Upper motor neurone facial weakness was present in $17 \%$ of the patients with a focal lesion, but it was always associated with other focal signs. The sensory examination alone rarely identified patients with a focal lesion. Sensory testing is time consuming and the findings are often difficult to interpret. For these reasons, the sensory examination is seldom helpful in detecting patients with focal brain disease in the outpatient setting.

It is difficult to blind examiners to the diagnosis in studies of clinical signs. We attempted to do this by including a control group and by blinding examiners to the history and the results of investigations. However, we cannot exclude the possibility that the examiners detected subtle clues that identified patients as having a focal lesion. The sensitivity of the neurological examination may have been improved by including more tests of cognitive function and language. However, a more comprehensive assessment of language may have unblinded the examiner if the history was revealed during the interview. Tests of memory may have detected abnormalities, but they would not have distinguished between patients with a focal lesion and those with diffuse or multifocal brain disease. If a larger number of patients had been recruited, it might have been possible to determine the sensitivity of clinical tests to detect lesions in the various lobes of the brain. The study also could have been improved if interobserver agreement had been measured. However, we believe that these drawbacks do not alter the interpretation of the main findings.

The low sensitivity of the neurological examination for the detection of a focal lesion in this study may not be surprising, because patients with obvious neurological signs were excluded. The patients in the focal lesion group had undergone a neurological examination by a neurologist or neurosurgeon before recruitment, and signs of a focal cerebral lesion had been detected in only about one third. If the clinical tests used in this study had been applied to an unselected group of patients with focal brain disease, the neurological examination might have been abnormal in a larger proportion. Most of the patients with a focal lesion in this study had tumours, which are less likely to cause focal signs than cerebrovascular disease. Our findings should not be extrapolated to populations with a higher proportion of patients with non-neoplastic focal brain disease. The results indicate that the examination alone cannot be relied on to determine whether a patient with neurological symptoms requires investigation. The history apparently plays an essential role in the decision to investigate these patients.

Detecting weakness resulting from an upper motor neurone lesion can be difficult, whereas tests for pronator drift, rapid alternating movements, and forearm and finger rolling may be easier to interpret. These tests may be helpful in detecting a focal lesion when used by non-neurologists, but this would need to be assessed in a separate study.

\section{Authors' affiliations}

N E Anderson, D F Mason*, J N Fink*, P S Bergin, A J Charleston, Department of Neurology, Auckland Hospital, Auckland, New Zealand G D Gamble, Department of Medicine, University of Auckland

*Current address: Neurology Department, Christchurch Hospital, Christchurch, New Zealand

Competing interests: none declared

\section{REFERENCES}

1 Sawyer RN, Hanna JP, Ruff RL, et al. Asymmetry of forearm rolling as a sign of unilateral cerebral dysfunction. Neurology 1993;43:1596-8.

2 Weaver DF. A clinical examination technique for mild upper motor neuron paresis of the arm. Neurology 2000;54:531-2.

3 Haerer AF. DeJong's The neurologic examination, 5th ed. Philadelphia: JB Lippincott Co, 1992.

4 Spillane JA. Bickerstaff's neurological examination in clinical practice, 6th ed. Oxford: Blackwell Science, 1996.

5 Yamamoto T. Forearm-rolling test. Neurology 1995;45:2299.

6 Baloh RW, Sills A, Honrubia V. Eye-tracking and optokinetic nystagmus: results of quantitative testing in patients with well-defined nervous system lesions. Ann Otol Rhinol Laryngol 1977;86:108-14.

7 David NJ. Optokinetic nystagmus. A clinical review. J Clin Neuro-ophthalmol 1989;9:258-66.

8 Newcombe RG. Two-sided confidence intervals for the single proportion: comparison of seven methods. Stat Med 1998;17:857-72.

9 Ross RT. How to examine the nervous system, 3rd ed. Stamford: Appleton and Lange, 1999.

10 Leigh RJ, Sawyer RN, Ruff RL. Forearm-rolling test: reply from the authors. Neurology 1995; 45:2299

11 Stell R, Davis S, Carroll WM. Unilateral asterixis due to a lesion of the ventrolateral thalamus. J Neurol Neurosurg Psychiatry 1994;57:116-18.

12 De Renzi E, Barbieri C. The incidence of the grasp reflex following hemispheric lesion and its relation to frontal damage. Brain 1992;115:293-313. 